\title{
BUSINESS PLAN: RENCANA PENDIRIAN KEDAI TEH DI JAKARTA BARAT
}

\author{
Leonita Wijaya \\ Program Studi Magister Manajemen Universitas Tarumanagara \\ leonitawijaya@gmail.com \\ Eddy Herjanto \\ Program Studi Magister Manajemen Universitas Tarumanagara
}

Masuk : 07-12-2019, revisi : 21-12-2019 diterima untuk diterbitkan : 23-12-2019

\begin{abstract}
Business Plan establishing an "Essence Tea Café at Jakarta Barat" is a planning for opening a business which sell tea for take away. With the lifestyle of the community, we can see a potential opportunity to sell drinks which are currently trending among teenagers to young executives. This business plan aims to create a new business plan in the food and beverage industry and create opportunities for profit. Based on the results of the analysis and discussion, it can be concluded that this business is feasible to be realized on the basis of considerations including Porter's Five Forces analysis and SWOT analysis. This business financial planning also shows that this business will provide profit and payback period which is quite short, i.e 1 year 4 months. And the Net Present Value (NPV) value of approximately Rp 440,000,000,- it shows that this investment is very profitable, and the Internal Rate of Return (IRR) value is $266 \%$, which means it is much higher than the interest rate.
\end{abstract}

Abstrak : "Perencanaan Bisnis Pendirian Kafe di Jakarta Barat" adalah rencana bisnis usaha yang menjual produk minuman teh take away. Dengan seiringnya gaya hidup masyarakat yang semakin meningkat, maka kita dapat melihat suatu peluang yang cukup potensial untuk menjual minuman kekinian yang saat ini sedang trend di kalangan anak remaja hingga eksekutif muda. Perencanaan bisnis ini bertujuan untuk membuat suatu rencana bisnis baru pada industri food and beverages serta menciptakan kesempatan untuk dapat menghasilkan keuntungan. Berdasarkan hasil analisa dan pembahasan, maka dapat disimpulkan bahwa bisnis ini layak direalisasikan dengan dasar pertimbangan antara lain analisis Porter's Five Forces dan analisis SWOT. Perencanaan keuangan bisnis ini juga menunjukan bahwa bisnis ini akan memberikan profit serta payback period yang cukup singkat yaitu 1 tahun 4 bulan. Dan nilai Net Present Value (NPV) dengan nilai Rp 440.173.246,- hal ini menunjukan investasi ini sangat menghasilkan dan menguntungkan, serta nilai Internal Rate of Return (IRR) sebesar $266 \%$ yang berarti jauh lebih tinggi dari nilai suku bunga.

Keywords : Business Plan, Food and Beverages, Payback Period, Net Present Value, Internal Rate of Return

\section{PENDAHULUAN}

Tahun 2019 adalah tahun ketiga semenjak peluncuran program Gerakan Kewirausahaan Nasional yang diluncurkan oleh pemerintah. Pengembangan kewirausahaan akan menyasar 8.790 calon wirausaha melalui pemasyarakatan kewirausahaan, pelatihan kewirausahaan, pelatihan technopreneur, dan kewirausahaan sosial. Hal ini bertujuan untuk meningkatkan kualitas SDM pelaku usaha. Pemerintah juga menggelar program peningkatan kualitas SDM koperasi bagi 4.530 pelaku koperasi melalui pelatihan perkoperasian, hingga peningkatan standarisasi dan sertifikasi bagi 2.010 pelaku koperasi dan UMKM melalui pelatihan dan uji sertifikasi kompetensi SDM Koperasi Usaha Kecil dan Menengah. Juga peningkatan kapasitas 
pengelola Lembaga Keuangan Mikro berbasis kompetensi dan pelatihan manajemen SDM KUKM berbasis kompetensi.

Tak hanya itu, dalam rangka mengefektifkan dan mengefisiensikan penyelenggaraan peningkatan SDM KUKM, Kemenkop tahun ini telah mengalokasikan anggaran untuk pelatihan dan pendampingan di kabupaten/kota melalui mekanisme Dana Alokasi Khusus (DAK). DAK tahun 2019 sebesar Rp200 miliar dialokasikan di 34 provinsi dan 172 kabupaten/kota di Indonesia, dengan sasaran peserta pelatihan sebanyak 56.056 orang dan pendamping sebanyak 1.279 orang (http://www.neraca.co.id/article/112565/2019).

Pada tahun 2019 jumlah wirausaha di Indonesia menembus 3,1 persen dari total jumlah penduduk yang saat ini sekitar 260 juta jiwa atau sekitar 8,06 juta jiwa, angka tersebut melampaui standar internasional sebanyak 2 persen. Walaupun demikian, jumlah wirausaha di Indonesia masih terbilang rendah, dibanding negara lain, seperti Singapura yang telah mencapai 7 persen dan Malaysia sebesar 5 persen(http://rri.co.id/post/berita/651422/ekonomi).

Bisnis minuman merupakan bisnis yang tidak ada matinya sampai saat ini bahkan semakin berkembang. Hal ini disebabkan minuman kekinian sudah menjadi lifestyle anak-anak muda di Ibukota Jakarta ini.

Berdasarkan data Badan Perencanaan Pembangunan Nasional (Bappenas) pada 2018, dari total populasi Indonesia sebesar 265 juta jiwa, millennial Indonesia atau penduduk berusia 20 sampai 35 tahun berjumlah 63 juta jiwa. Di daerah Jakarta sendiri terdapat kaum millennial sebanyak 2 juta penduduk.

Gaya hidup seperti saat ini berpotensi menjadi peluang bisnis yang cukup besar dan dapat dilihat bahwa jumlah populasi millennial di Jakarta cukup tinggi. Penelitian ini dibuat sebagai rencana usaha mendirikan kafe yang diberi nama essence. Rencananya essence ini akan didirikan di daerah pusat keramaian seperti kampus Universitas Tarumanagara, Mercu Buana dan Binus University.

\section{TUJUAN}

Berdasarkan latar belakang dan masalah penelitian di atas, maka tujuan penelitian ini adalah membuat sebuah rencana bisnis yang dapat menjelaskan tentang:

1. Analisis terhadap industri (Porter's five forces model) dan analisis persaingan (analisis SWOT) pada usaha Essence.

2. Analisis kelayakan investasi pendirian Essence dapat memenuhi tingkat pengembalian yang diharapkan oleh investor yang tercermin dari nilai ROI, NPV dan IRR.

3. Periode jangka waktu pengembalian investasi dari business plan ini.

\section{METODE PENELITIAN}

Penelitian yang dilakukan dalam rencana bisnis Essence menggunakan dua metode yaitu studi lapangan (field research) dan studi pustaka (library research).

Studi lapangan bertujuan untuk mendapatkan gambaran kondisi nyata lingkungan bisnis yang terjadi pada saat rencana bisnis Essence akan berjalan nantinya. Data yang dihasilkan dari studi lapangan ini akan menjadi data primer dalam rencana bisnis yang akan dibuat. Sedangkan studi pustaka digunakan untuk mendapatkan teori-teori pendukung yang berguna sebagai acuan teori bagi analisis dan pengolahan data. Data dari studi pustaka ini disebut juga data sekunder. Gabungan dari studi lapangan dan studi pustaka diharapkan dapat saling berintegrasi dan saling menguatkan sehingga menghasilkan rencana bisnis yang akurat dan dapat diaplikasikan.

\section{RENCANA BISNIS}

Rencana bisnis "Essence Café" diawali dengan data input yaitu mengumpulkan data hasil observasi terhadap pihak-pihak terkait, rencana kebutuhan biaya investasi, biaya operasional, dan asumsi penetapan pendapatan. Selain itu juga ditambahkan data-data dari instansi lain yang terkait dengan rencana bisnis ini. 
Tahap berikutnya adalah proses analisis yang terbagi dua menjadi analisis kualitatif dan kuantitatif. Analisi kualitatif meliputi analisis perusahaan, analisis industri, analisis eksternal, analisis produk, harga, tempat dan promosi (4P), analisis segmenting, targeting, dan positioning (STP), rencana operasional dan SDM, dan konsep waralaba. Sedangkan yang termasuk analisis kuantitatif meliputi proyeksi laporan keuangan (neraca, laba rugi, dan arus kas), net present value, internal rate of return, payback period, discounted payback period, profitability index, dan sensitivity analysis.

Setelah analisis kualitatif dan kuantitatif dilakukan, maka tahap terakhir adalah menentukan output yang berisi hasil-hasil dari setiap analisis dan membuat kesimpulan yang akan berpengaruh terhadap keputusan para pemegang modal usaha.

\section{ANALISIS SWOT}

Analisis SWOT sangat diperlukan pada saat melakukan suatu usaha baru yang berguna untuk mengetahui kekuatan dan kelemahan dari bisnis yang akan dibuat agar perusahaan mampu membuat strategi yang paling tepat, guna meraih semua peluang dan mengeliminir kelemahan-kelemahan yang ada. Analisis SWOT essence diuraikan pada tabel di bawah ini:

\begin{tabular}{|l|l|}
\hline Strength (Kekuatan) & $\begin{array}{l}\text { a. Kedai Teh dan sejenisnya belum menjamur seperti kedai } \\
\text { kopi pada saat ini } \\
\text { b. Sangat jarang café yang memiliki menu teh bervariasi } \\
\text { c. Sangat jarang terdapat kedai teh yang memberikan } \\
\text { kualitas tinggi dengan harga terjangkau. }\end{array}$ \\
\hline Weakness (Kelemahan) & $\begin{array}{l}\text { d. Sebagai pemain baru, masyarakat masih belum mengenal } \\
\text { produk ini. } \\
\text { e. Pengeluaran biaya cukup tinggi terutama dalam masalah } \\
\text { pemasaran. }\end{array}$ \\
\hline Opportunities (Peluang) & $\begin{array}{l}\text { f. Peluang kerja sama dengan pemilik brand teh yang sudah } \\
\text { terkenal. }\end{array}$ \\
\hline Threats (Ancaman) & $\begin{array}{l}\text { g. Adanya kompetitor yang membuat bisnis serupa. } \\
\text { h. Selera konsumen yang berubah }\end{array}$ \\
\hline
\end{tabular}

\section{KEBUTUHAN INVESTASI DAN MODAL KERJA}

Total biaya investasi dan biaya operasional 1 tahun pertama yang dibutuhkan untuk menjalankan bisnis kedai teh sebesar Rp 252.750.000,- yang akan digunakan dalam dua komponen biaya yaitu biaya pembelian aktiva dan biaya operasional.

\begin{tabular}{|c|c|c|c|}
\hline Deskripsi & Unit & Harga & Total Harga \\
\hline \multicolumn{4}{|l|}{ Fixed Asset } \\
\hline Tea Maker & 10 & 450.000 & 4.500 .000 \\
\hline Stove & 1 & 400.000 & 400.000 \\
\hline Cup Sealer & 1 & 750.000 & 750.000 \\
\hline Water Pump & 1 & 100.000 & 100.000 \\
\hline Cashier Machine & 1 & 5.000 .000 & 5.000 .000 \\
\hline Sink & 1 & 1.000 .000 & 1.000 .000 \\
\hline CCTV & 2 & 2.000 .000 & 4.000 .000 \\
\hline $\mathrm{AC}$ & 1 & 3.500 .000 & 3.500 .000 \\
\hline \multicolumn{2}{|c|}{ Total Fixed Asset } & \multicolumn{2}{|r|}{19.250 .000} \\
\hline \multicolumn{4}{|l|}{ Variable Cost } \\
\hline Salary & 13 & 7.500 .000 & 97.500 .000 \\
\hline Rent /year & 1 & 60.000 .000 & 60.000 .000 \\
\hline Electricity, Water & 12 & 750.000 & 9.000 .000 \\
\hline
\end{tabular}




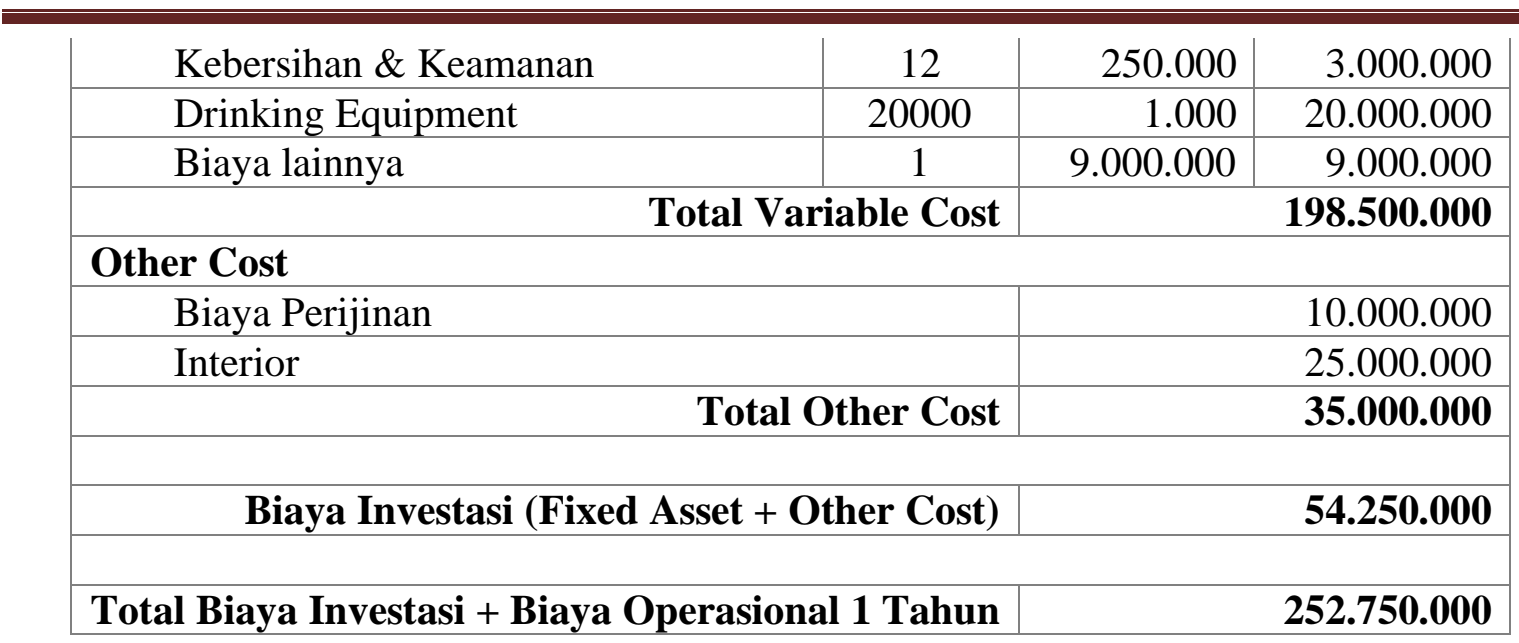

\section{PROYEKSI LABA RUGI}

\begin{tabular}{|c|c|c|c|c|c|}
\hline Profit \& Loss & 2020 & 2021 & 2022 & 2023 & 2024 \\
\hline Revenue & 369.360 .000 & 554.040 .000 & 831.060 .000 & 997.272.000 & 1.196 .726 .400 \\
\hline COGS & 203.148 .000 & - 304.722 .000 & - 457.083 .000 & 548.499 .600 & 658.199 .520 \\
\hline Gross Profit & 166.212 .000 & 249.318.000 & 373.977.000 & 448.772.400 & 538.526.880 \\
\hline SG\&A & 186.350 .000 & - 195.800 .000 & - 206.195.000 & 217.629 .500 & 230.207 .450 \\
\hline Operating Profit & 20.138.000 & 53.518.000 & 167.782 .000 & 231.142.900 & 308.319 .430 \\
\hline \multicolumn{6}{|c|}{ Other Income/Expense } \\
\hline Pretax Income & $\begin{array}{l}-\quad 20.138 .000\end{array}$ & 53.518.000 & 167.782 .000 & 231.142.900 & 308.319.430 \\
\hline Tax & 5.034 .500 & 13.379 .500 & 41.945 .500 & 57.785 .725 & 77.079 .858 \\
\hline Net Income & - $\quad 25.172 .500$ & 40.138.500 & 125.836.500 & 173.357.175 & 231.239.573 \\
\hline
\end{tabular}

\section{TABEL PROYEKSI GABUNGAN}

\begin{tabular}{|c|c|c|c|c|c|}
\hline & 2021 & 2022 & 2023 & 2024 & 2025 \\
\hline Net Income & 25.172 .500 & 40.138 .500 & 125.836 .500 & 173.357 .175 & 231.239 .573 \\
\hline \multirow[t]{2}{*}{ Interest Rate } & $7 \%$ & $7 \%$ & $7 \%$ & $7 \%$ & $7 \%$ \\
\hline & 25.172 .500 & 37.512 .617 & 109.910 .473 & 141.511 .094 & 176.411 .563 \\
\hline NPV & & & & & 440.173.246 \\
\hline IRR & \multicolumn{5}{|c|}{$266 \%$} \\
\hline Payback Period & \multicolumn{5}{|c|}{1 Tahun 4 Bulan } \\
\hline
\end{tabular}




\section{KESIMPULAN}

Berdasarkan analisis Porter's Five Forces dan analisis SWOT yang telah dilakukan dapat disimpulkan bahwa industri ini masih menarik bagi investor untuk dijadikan sumber pendapatan apalagi ditunjang dengan dukungan pemerintah yang akan menggiatkan kewirausahaan serta mengembangkan bisnis usaha food and beverages.

Berdasarkan analisis keuangan dan kelayakan investasi dengan menggunakan bisnis ini dapat memberikan NPV sebesar Rp 440.173.246 dan IRR sebesar 266\%.

Lamanya periode pengembalian investasi yaitu selama 1 tahun 4 bulan.

\section{DAFTAR PUSTAKA}

David, Fred., (2007). Strategic management: Concept and cases international version. Pearson Higher Education.

David, H. Bangs Jr (2005). Business plans made easy, $3^{\text {rd }}$. Entrepreneur press.

Ireland R. Duane., Robert E. Hoskisson, Michael A. Hitt. The Management of strategy: Concepts and cases. 9th ed. South Western, 2011.

Johnson, G and Scholes, K., (2002). Exploring corporate strategy, $6^{\text {th }}$ edition, Prentice Hall. Kasali, Rhenald., (1998). Membidik pasar Indonesia: Segmentasi, Targeting, Positioning. PT Gramedia Pustaka Utama.

Kasali, Rhenald., (2011). Cracking zone. PT Gramedia Pustaka Utama.

Kasmir dan Jakfar, (2003). Studi kelayakan bisnis, edisi pertama. Prenada Media

Kotler, Philip. Marketing management. 13th edition. New Jersey: Prentice Hall, Inc, 2009.

Megginson, L.C., Byrd, M.J., \& Megginson, W.L. (2003). Small business management: An entrepeneur's guidebook, ( $4^{\text {th }}$ ed). New York: McGraw-Hill

Peterson \& Fabozi (2002). Capital budgeting theori and practise. Wiley Finance.

Porter, M. E., (1985). Competitive advantage. The Free Press, New York, NY.

Porter, M. E., (1998). Competitive strategy: Technique for analysing industries and competitors. The Free Press, New York, NY.

Primartantyo, Ukky (2011). Indonesia butuh 4.1 juta wirausaha baru. 14 Desember 2011. http://tempo.co/read/news/2011/12/14/089371713

Ross, S.A. et al (2009). Modern financial management, $8^{\text {th }}$ edition. New York: McGraw-Hill Shapiro (2005). Capital Budgeting and Investment Analysis. Pearson, Prentice Hall 